\title{
Cardiomyocyte Reprogramming: A Potential Strategy for Cardiac Regeneration
}

\author{
Marshell Tendean ${ }^{1}$, Yudi Her Oktaviono², Ferry Sandra ${ }^{3,4}$ \\ ${ }^{1}$ Department of Internal Medicine, Faculty of Medicine, Krida Wacana Christian University, Jakarta, Indonesia \\ ${ }^{2}$ Department of Cardiology and Vascular Medicine, Faculty of Medicine, Dr. Soetomo General Hospital / University of Airlangga, \\ Surabaya, Indonesia \\ ${ }^{3}$ Department of Biochemistry and Molecular Biology, Division of Oral Biology, Faculty of Dentistry, Trisakti University, Jakarta, \\ Indonesia \\ ${ }^{4}$ Doctoral Program in Medical Science, Faculty of Medicine, University of Sumatera Utara, Medan, Indonesia
}

Heart disease is the leading cause of death worldwide. Within decades a limited process of cardiac cell regeneration was under observation. Embryonic stem cell (ESC) shows great potential for cell and tissue regeneration. Studies indicate that ESC has the potential to enhance myocardial perfusion and/or contractile performance in ischemic myocardium. However there is still challenge to evaluate the issues of teratoma. Then induced pluripotent stem cell was invented by introducing four transcriptional factors (Oct4, Sox2, KIf4, c-Myc). iPSC was created from murine fibroblast and then differentiated into cardiomyocyte. Reprogramming the adult cell could be performed in full, partial or direct reprogramming. Several studies add the significance by reprogramming the cells through more efficient techniques. However several limitations are still remained.

Keywords: cardiomyocyte, reprogramming, iPSC, fibroblast

\section{Introduction}

Heart disease in the form of ischemic heart disease and heart failure is the leading cause of death worldwide, with estimated $>7$ million death in $2012 .{ }^{1}$ Recent treatment strategy is to augment cardiac reperfusion so that can improve patient outcome and reduce morbidity due to heart failure, yet showing various efficacies. ${ }^{2}$ The loss of cardiac tissue diminish the properties of the heart to contract normally. ${ }^{3}$ The limited ability of human heart to regenerate, thus "regenerative medicine" represents as an alternative "second generation" treatment for ischemic heart disease. ${ }^{4}$

Date of submission: May 11, 2016

Last Revised: July 1, 2016

Accepted for publication: July 20, 2016

\section{Corresponding Author:}

Ferry Sandra

Department of Biochemistry and Molecular Biology, Division of Oral Biology

Faculty of Dentistry, Trisakti University, Jl. Kyai Tapa No.260

Jakarta, Indonesia

E-mail: ferrysandra@gmail.com
This approach may encompass cardiomyocyte regeneration, neovascularization, and paracrine cytokines. ${ }^{3}$

Adult heart is dominated by fibroblast and less population of cardiomyocyte. During a cardiac event or injury, fibroblast activation leads to fibrosis, which contribute to heart failure or conduction abnormalities. ${ }^{5}$ Transplantation of different cells has been proposed to augment cardiac regeneration. The introduction of MyoD gene in fibroblast stimulated trans-differentiation into skeletal muscle. ${ }^{2}$ More recent work on cardiomyocyte regeneration has focused on cell originated from pluripotent embryonic stem cell (ESC) ${ }^{6}$ or induced pluripotent stem 
cell (iPSC) $)^{7,8}$ and adult progenitor cell located in the heart termed as resident cardiac progenitor cells (CPC) or in non cardiac-sites (non-resident CPC).

This review will discuss various cardiac cell reprogramming, initially iPSC, a method to reprogram somatic cell into pluripotent stem cell, ${ }^{7}$ then partial reprogramming through $\mathrm{CPC},{ }^{9}$ and direct reprogramming method which aim to directly convert the mature (unipotent) fibroblast to cardiomyocyte without going through iPSC type. ${ }^{10}$ Furthermore we will discuss the benefit and future use of cardiac reprogramming in heart disease.

\section{Cardiomyocyte regeneration}

Several vertebrae like axolotl, ${ }^{11}$ zebrafish and newt, ${ }^{12}$ are evident to have significant regeneration capacity of the heart. This ability is also found transiently in mice during the first week of their live. ${ }^{13}$ Shortly after birth, human myocardium growth transition from hyperplastic to hypertrophic phase, characterized by the presence of binucleated cardiomyocyte. Indicating the cardiomyocyte differentiation already terminated. ${ }^{14}$ However this concept has been changed recently, ${ }^{14} \mathrm{C}$ was used to carbon date the DNA of proliferating cardiomyocyte. Limited regeneration of human cardiomyocyte from pre-existing cardiomyocyte was confirmed, approximately $1 \%$ per year and $0.4 \%$ per year at age 20 and 75 respectively. ${ }^{15} \mathrm{~A}$ similar rate of cardiogenesis in young human adults was recently confirmed (1.9\% at 20 years) and declined after 20 years old with the loss of cytokinetic ability. ${ }^{16}$ Based on this, about $45 \%$ would be renewed over the normal human lifespan and more significance in woman compare to male population, 15 to 11 times cardiomyocyte turnover respectively. ${ }^{17}$

\section{Cardiopoesis and self-generating cells}

The natural response for cardiac tissue damage is reinforcement of stem cells programming to lineagespecifying cardiovascular-derived defined as cardiopoiesis. ${ }^{18}$ Cardiopoiesis guides stem cells to re-activate cellular plasticity, re-engage into cardiovasculogenesis, and re-set an active propensity for repair. Many type of stem cells already tested to measure their ability to regenerate: adult cells (umbilical cord blood mononuclear cell, ${ }^{19-21}$ bone marrowderived mesenchymal stem cell, ${ }^{22,23}$ resident or endogenous cardiac stem cell, ${ }^{24}$ endothelial progenitor cell $^{25-28}$ ); and ESC or iPSC which shows great potentials. ${ }^{7,29}$ Preliminary studies indicate that ESC has the potential to enhance myocardial perfusion and/or contractile performance in ischemic myocardium. However there is still challenge to evaluate the issues of teratoma ${ }^{22}$ and what actually drives the improvement of cardiac function after the application ESC..$^{30}$ In the other hand to maintain cardiopoesis, small molecules in the form of growth factors or cytokines such as fibroblast growth factor (FGF), vascular endothelial growth factor (VEGF), erythropoietin (EPO) or granulocyte colony stimulating factor (G-CSF) also introduced to enhance the mobilization of progenitor cells. ${ }^{27-29}$

\section{Novel cell sources "cardiomyocyte from ESC or iPSC"}

ESC is undiffentiated, pluripotent and self-renewing cell in appropriate culture condition, which give rise to three embryonic germ layers. The gene expression of ESCderived cardiomyocyte resembles mammalian heart and become mature with time. ${ }^{31}$ In order to reduce immune graft rejection, generation of allogeneic patient-specific cells are warranted.

A novel approach with four transcription factors Oct4, Sox2, Klf4 and c-Myc create ESC-like cells or iPSC. Development to reprogram cardiomyocyte from omnipotent/ adult cells could be performed in three strategies (Figure 1) ${ }^{32}$ : 1. Full reprogramming of the iPSC and subsequent cardiac differentiation. 2. Partial reprogramming of fibroblast to cardiac progenitor cells and subsequent differentiation, and 3. Direct reprogramming into cardiomyocyte. ${ }^{2,32}$ Generatedcardiomyocte can be cultivated ex-vivo than transplanted into infarcted tissue or induction of cardiomyocyte in vivo with various recognized transcription factors or microRNA (miR).

\section{Full reprogramming}

ESC is known to reliably give rise to cardiomyocyte in vitro. This pluripotent cell can be propagated in undiffentiated state and then coaxed to variety of cell lineages. ${ }^{33}$ Nevertheless, the inability to create patient- or disease-specific ESC from adult individual and immune rejection-associated with allogeneic cell transplant raise the limitation when translated to clinical use.

The introduction of four transcription factors ${ }^{7,34}$ become the major revolution in regenerative medicine. This strategy required full reprogramming of fibroblasts into 
iPSCs, and subsequent differentiation to cardiomyocyte, which take a long period (months). Functional analyses of iPSC-derived cardiomyocyte demonstrate that they are embryonic or immature cardiomyocyte rather than adult type cardiomyocyte. ${ }^{32}$ At present cardiomyocyte derived from human iPSC is used for disease modeling.

\section{Partial reprogramming}

One of the limitations in using the iPSC approach is the duration, which may take a few months to complete the processes including fibroblast expansion and reprogramming, expanding the generated iPSC colonies, and finally differentiate into the cardiac lineage. ${ }^{7}$ To overcome this limitation, overexpression of Oct4, Sox2, and Klf4, c-Myc in murine fibroblast was performed in short incubation period with cardio-inductive medium by adding growth factor bone morphogenetic protein (BMP)4 and an inhibitor of Janus kinase (JAK) to further prevent development of pluripotent lineage. ${ }^{9}$ Using this strategy cardiomyocyte generation can be shortened within 1112 days. However, it is still unrevealed how the partially reprogrammed cardiomyocyte compare with those derived from pluripotent stem cell lines, in terms of their cardiomyocyte phenotypic properties and their capacity for cardiac repair.

\section{Direct reprogramming}

Direct reprogramming fibroblast into induced cardiomyocyte (iCM) can be performed by adding some combination of gene specific transcription factors (Gata4, Mef2c, Tbx5, Hand2, Myocd, etc.) into cardiac fibroblast, tail tip fibroblast (TTF) or mouse embryonic fibroblast (MEF). These transcription factors were introduced using viral vectors (retroviruses, lentiviruses, adenoviruses, etc.); or lipofection method to transfect cells with cardiac specific miR. ${ }^{32} \mathrm{iCM}$ can be produced by adding a combination of three developmental transcription factors (Gata4, Mef2c, $T b \times 5)^{10}$ or four transcription factors (Gata4, Mef2c, Hand2, Tbx5). ${ }^{35}$ However evaluation to suitable $\mathrm{iCM}$ is still remained a challenge. Interestingly, combination of $M e f 2 c$, Tbx5, Myocd, resulted in a more developed cardiomyocyte. ${ }^{36}$

When translated in vivo, the application of Gata4, Mef2c, Tbx5 in vivo in 2 month infarcted mice using retroviral, showed a decreased infarct size and improvement in cardiac function. ${ }^{37}$ Transduction with retroviruses contain

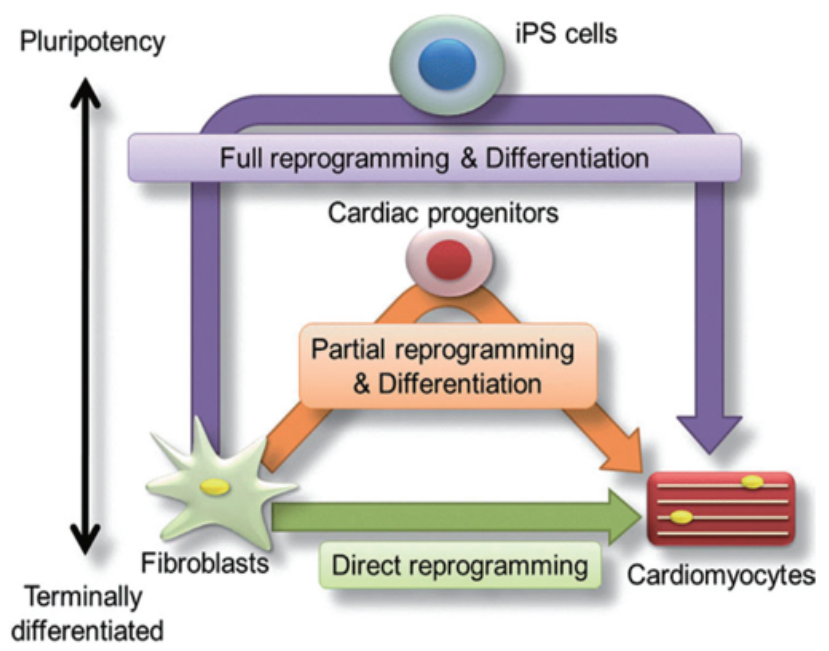

Figure 1. Three different pathways of emerging cardiomyocyte regeneration which include a full reprogramming approach (purple line), a partial reprogramming approach (orange line), and a direct reprogramming approach (green line). ${ }^{32}$ (Adapted with permission from International Heart Journal).

four transcription factors Gata4, Hand2, Mef2c Tbx5 to cardiac fibroblast in vivo showed an increase of iCM like cell (9.2\%), almost 4-fold higher compared with Gata4, Mef2c, Tbx5 (2.5\%). ${ }^{35}$ In addition, in vivo iCMs express more fully reprogrammed than their in vitro counterparts, suggest an unrevealed factors that enhance reprogramming. ${ }^{35,37}$

The potential of miR for differentiating pluripotent stem cells to cardiovascular lineage was recognized. ${ }^{38} \mathrm{By}$ introducing miR (miR-1, miR-133, miR-208, and miR-499) into neonatal cardiac fibroblasts, iCMs could be resulted directly in vitro and in vivo. Application of miR was enhanced by JAK inhibitor treatment. The miR-mediated induction found to be safer for applications in humans. ${ }^{39}$ Compared with Gata4, Mef2c, Tbx5 merely, miR and Gata4, Mef2c, Tbx 5 combination produce 7-fold beating iCMs and shorten the duration in inducing beating cells. ${ }^{40}$

\section{From translational research to human application in vivo}

There were three studies in direct reprogramming of fibroblasts. ${ }^{41-43}$ Combination of four transcription factors (Gata4, Hand2, Tbx5, and Myocd) and two muscle-specific miRs (miR-1 and miR-133), could reprogram up to $20 \%$ of fibroblast into $\mathrm{cTnT}^{+}$cells. Furthermore, a subset of iCMs demonstrated spontaneous beating after 11 weeks in culture. ${ }^{43}$ Similarly, a mixture of seven transcription factors (Gata4, Mef2c, Tbx5, Mesp1, Myocd, Zfpm2, 
Esrrg) gene expression in fibroblasts lead to iCM. ${ }^{42}$ This work demonstrated that this mixture of reprogramming factors made human iCMs epigenetically stable, and that transforming growth factor (TGF)- $\beta$ signaling improved the efficiency of human iCMs reprogramming. ${ }^{42}$ Finally, iCMs resulted from reprogramming human fibroblast with a combination of five transcription factors (Gata4, Mef2c, Tbx5, Mesp1, Myocd) demonstrated action potentials and beating when co-cultured with rat cardiomyocyte. ${ }^{41}$ Besides all stated transcription factor, ETS-2 was also used in combination with Mesp1 for fibroblast treated with activin A and BMP2 to reprogram human dermal fibroblasts into cardiac progenitor-like cells, which can differentiate into iCMs. ${ }^{44}$ Despite these promising features, direct cardiac reprogramming is less efficient in human cells compared to murine fibroblasts. An optimized combination of appropriate transcription factors and miRs for direct human cardiac reprogramming is required, as well as preconditioning for human cardiomyocyte.

\section{Future issues and challenges}

Reprogramming process though promising still lead with several limitations especially in terms of teratoma formation, ${ }^{32}$ differentiation efficiency, the specificity of cardiomyocyte phenotype, ${ }^{34}$ long term survival of the cells and immune graft rejection. ${ }^{45}$ Many factors are yet to be revealed in favor to generate efficient reprogramming. Applying hypoxic environment or directly introduce in vivo are reported to increase the possibility of new cardiomyocyte. ${ }^{46}$ Further research and validation of methods are necessary.

\section{Conclusion}

Through full, partial or direct reprogramming, adult cardiomyocyte can be generated in vitro or in vivo by adding several transcriptional factors. Many limitation considered regarding most efficient and standardization of protocols before translated to clinical practice.

\section{References}

1. Department of Health Statistics and Informatics in the Information, Evidence and Research Cluster of WHO. The Global Burden of Disease: 2004 Update. Geneva; 2008.

2. Lin $\mathrm{Z}, \mathrm{Pu} \mathrm{WT}$. Strategies for Cardiac Regeneration and Repair. Sci Transl Med. 2014; 6(239): 239rv1. doi: 10.1126/ scitranslmed.3006681
3. Steinhauser ML, Lee RT. Regeneration of the Heart. EMBO Mol Med. 2011; 3(12): 701-12.

4. Li N, Wang C, Jia L, Du J. Heart Regeneration, Stem Cells, and Cytokines. Regen Med Res. 2014; 2: 6. doi: 10.1186/2050-490X-26.

5. Nam YJ, Song K, Olson EN. Heart Repair by Cardiac Reprogramming. Nat Med. 2013; 19: 413-5.

6. Mummery C, Ward-van Oostwaard D, Doevendans P, Spijker R, van den Brink S, Hassink R, et al. Differentiation of Human Embryonic Stem Cells to Cardiomyocytes: Role of Coculture with Visceral Endoderm-Like Cells. Circulation 2003; 107: 2733-40.

7. Takahashi K, Yamanaka S. Induction of Pluripotent Stem Cells from Mouse Embryonic and Adult Fibroblast Cultures by Defined Factors. Cell 2006; 126(4): 663-76.

8. Fujita J, Fukuda K. Future Prospects for Regenerated Heart Using Induced Pluripotent Stem Cells. J Pharmacol Sci. 2014; 125(1): 1-5.

9. Efe JA, Hilcove S, Kim J, Zhou H, Ouyang K, Wang G, et al. Conversion of Mouse Fibroblasts into Cardiomyocytes Using a Direct Reprogramming Strategy. Nat Cell Biol. 2011; 13: 215-22.

10. Ieda M, Fu JD, Delgado-Olguin P, Vedantham V, Hayashi Y, Bruneau BG, et al. Direct Reprogramming of Fibroblasts into Functional Cardiomyocytes by Defined Factors. Cell. 2010; 142(3): 375-86.

11. Cano-Martínez A, Vargas-González A, Guarner-Lans V, PradoZayago E, León-Oleda M, Nieto-Lima B. Functional and Structural Regeneration in the Axolotl Heart (Ambystoma Mexicanum) after Partial Ventricular Amputation. Arch Cardiol Mex. 2010; 80(2): 7986.

12. Oberpriller JO, Oberpriller JC. Response of the Adult Newt Ventricle to Injury. J Exp Zool. 1974; 187(2): 249-59.

13. Porrello ER, Mahmoud AI, Simpson E, Hill JA, Richardson JA, Olson EN, et al. Transient Regenerative Potential of the Neonatal Mouse Heart. Science. 2011; 331(6020): 1078-80.

14. Pasumarthi KBS, Field LJ. Cardiomyocyte Cell Cycle Regulation. Circ Res. 2002; 90: 1044-54.

15. Bergmann O, Zdunek S, Felker A, Salehpour M, Alkass K, Bernard $\mathrm{S}$, et al. Dynamics of Cell Generation and Turnover in the Human Heart. Cell 2015; 161(7): 1566-75.

16. Mollova M, Bersell K, Walsh S, Savla J, Das LT, Park SY, et al. Cardiomyocyte Proliferation Contributes to Heart Growth in Young Humans. Proc Natl Acad Sci. 2013; 110(4): 1446-51.

17. Kajstura J, Gurusamy N, Ogórek B, Goichberg P, Clavo-Rondon C, Hosoda T, et al. Myocyte Turnover in the Aging Human Heart. Circ Res. 2010; 107: 1374-86.

18. Behfar A, Yamada S, Crespo-Diaz R, Nesbitt JJ, Rowe LA, PerezTerzic C, et al. Guided Cardiopoiesis Enhances Therapeutic Benefit of Bone Marrow Human Mesenchymal Stem Cells in Chronic Myocardial Infarction. J Am Coll Cardiol. 2010; 56(9): 721-34.

19. Moenadjat Y, Merlina M, Surjadi CF, Sardjono CT, Kusnadi Y, Sandra F. The Application of Human Umbilical Cord Blood Mononuclear Cells in the Management of Deep Partial Thickness Burn. Med J Indones. 2013; 22(2): 92-9.

20. Djuwantono T, Wirakusumah FF, Achmad TH, Sandra F, Halim D, Faried A. A Comparison of Cryopreservation Methods: SlowCooling vs. Rapid-Cooling Based on Cell Viability, Oxidative Stress, Apoptosis, and CD34+ Enumeration of Human Umbilical Cord Blood Mononucleated Cells. BMC Res Notes. 2011; 4: 371. doi: 10.1186/1756-0500-4-371.

21. Wijaya MT, Sandra F. Proses dalam Umbilical Cord Blood Banking. CDK. 2007; 34(157): 217-20. 
22. Murry CE, Palpant NJ, Maclellan WR. Cardiopoietry in Motion: Primed Mesenchymal Stem Cells for Ischemic Cardiomyopathy. J Am Coll Cardiol. 2013; 61(23): 2339-40.

23. Lubis AM, Sandhow L, Lubis VK, Noor A, Gumay F, Merlina M, et al. Isolation and Cultivation of Mesenchymal Stem Cells from Iliac Crest Bone Marrow for Further Cartilage Defect Management. Acta Med Indones. 2011; 43(3): 178-84.

24. Siu CW, Tse HF. Cardiac Regeneration: Messages from CADUCEUS. Lancet.2012; 379(9819): 870-1.

25. Oktaviono YH, Sargowo D, Widodo MA, Dirgantara Y, Chouw A, Sandra F. Proliferation of Peripheral Blood-derived Endothelial Progenitor Cells from Stable Angina Subjects. Indones Biomed J. 2014; 6(2): 91-6.

26. Sandra F, Oktaviono YH, Widodo MA, Dirgantara Y, Chouw A, Sargowo D. Endothelial Progenitor Cells Proliferated via MEKdependent p42 MAPK Signaling Pathway. Mol Cell Biochem. 2015; 400(1): 201-6.

27. Nababan SHH, Purba AP, Frisca, Aini N, Setiawan B, Sandra F. Peranan Endothelial Progenitor Cell dalam Neovaskularisasi. CDK. 2007; 34(5): 257-9.

28. Frisca, Sardjono CT, Sandra F. Berbagai Paradigma Pendefinisian Endothelial Progenitor Cells. JKM. 2008; 8(1): 78-86.

29. Doppler SA, Deutsch MA, Lange R, Krane M. Cardiac Regeneration: Current Therapies-Future Concepts. J Thorac Dis. 2013; 5(5): 68397.

30. Dixit P, Katare R. Challenges in Identifying the Best Source of Stem Cells for Cardiac Regeneration Therapy. Stem Cell Res Ther. 2015; 6: 26. doi: 10.1186/s13287-015-0010-8.

31. Ieda M. Heart Regeneration Using Reprogramming Technology. Proc Jpn Acad Ser B Phys Biol Sci. 2013; 89(3): 118-28.

32. Yamakawa H, Ieda M. Strategies for Heart Regeneration: Approaches Ranging from Induced Pluripotent Stem Cells to Direct Cardiac Reprogramming. Inter Heart J. 2015; 56(1): 1-5. doi: 10.1536/ ihj.14-344.

33. Budniatzky I, Gepstein L. Concise Review: Reprogramming Strategies for Cardiovascular Regenerative Medicine: from Induced Pluripotent Stem Cells to Direct Reprogramming. Stem Cells Trans1 Med. 2014; 3(4): 448-57.

34. Takahashi K, Tanabe K, Ohnuki M, Narita M, Ichisaka T, Tomoda $\mathrm{K}$, et al. Induction of Pluripotent Stem Cells from Adult Human Fibroblasts by Defined Factors. Cell. 2007; 131(5): 861-72.
35. Song K, Nam Y, Luo X, Qi X, Tan W, Huang GN, et al. Heart Repair by Reprogramming Non-Myocytes with Cardiac Transcription Factors. Nature. 2012; 485: 599-604.

36. Protze S, Khattak S, Poulet C, Lindemann D, Tanaka EM, Ravens U. A New Approach to Transcription Factor Screening for Reprogramming of Fibroblasts to Cardiomyocyte-Like Cells. J Mol Cell Cardiol. 2013; 53(3): 323-32.

37. Qian L, Huang Y, Spencer CI, Folay A, Vedantham V, Liu L et al. In Vivo Reprogramming of Murine Cardiac Fibroblasts into Induced Cardiomyocytes. Nature. 2012; 485: 593-8.

38. Jakob P, Landmesser U. Role of microRNAs in Stem/Progenitor Cells and Cardiovascular Repair. Cardiovasc Res. 2012; 93(4): 614-22.

39. Jayawardena TM, Egemnazarov B, Finch EA, Zhang L, Payne JA, Pandya K, et al. MicroRNA-Mediated In Vitro and In Vivo Direct Reprogramming of Cardiac Fibroblasts to Cardiomyocytes. Circ Res. 2013; 110(11): 1465-73.

40. Muraoka N, Yamakawa H, Miyamoto K, Sadahiro T, Umei T, Isomi $\mathrm{M}$, et al. MiR-133 Promotes Cardiac Reprogramming by Directly Repressing Snail and Silencing Fibroblast Signatures. EMBO J. 2014; 33(14): 1565-81

41. Wada R, Muraoka N, Inagawa K, Yamakawa H, Miyamoto K, Sadahiro T, et al. Induction of Human Cardiomyocyte-like Cells from Fibroblasts by Defined Factors. Proc Natl Acad Sci. 2013; 110(31): 12667-72.

42. Fu JD, Stone NR, Liu L, Spencer CI, Qian L, Hayashi Y, et al. Direct Reprogramming of Human Fibroblasts Toward a Cardiomyocytelike State. Stem Cell Reports. 2013: 1(3): 235-47.

43. Nam YJ, Song K, Luo X, Daniel E, Lambeth K, West K, et al. Reprogramming of Human Fibroblasts Toward a Cardiac Fate. Proc Natl Acad Sci. 2013; 110(14): 5588-93.

44. Islas JF, Liu Y, Weng KC, Robertson MJ, Zhang S, Prejusa A, et al. Transcription Factors ETS2 and MESP1 Transdifferentiate Human Dermal Fibroblasts into Cardiac Progenitors. Proc Natl Acad Sci. 2012; 109(32): 13016-21.

45. Garbern JC, Lee RT. Cardiac Stem Cell Therapy and The Promise of Heart Regeneration. Cell Stem Cell. 2013; 12(6): 689-98.

46. Palazzolo G, Quattrocelli M, Toelen J, Dominici R, Anastasia L, Tettamenti G, et al. Cardiac Niche Influences the Direct Reprogramming of Canine Fibroblasts into Cardiomyocyte-like Cells. Stem Cells Int. 2016; 2016. 